\title{
High prevalence of adverse prognostic genetic aberrations and unmutated $I G H V$ genes in small lymphocytic lymphoma as compared to chronic lymphocytic leukemia
}

\author{
Patricia J. T. A. Groenen • Reinier Raymakers • Paul D. M. Rombout • \\ Martijn de Prenter • Linda Kossen • Corine Philipsen-Jansen • Ton Feuth • \\ Jos W. R. Meijer • Ad Geurts van Kessel • Johan H. J. M. van Krieken • \\ Marian Stevens-Kroef
}

Received: 23 June 2011 / Accepted: 9 August 2011 /Published online: 1 September 2011

(C) Springer-Verlag 2011

\begin{abstract}
According to the WHO classification, chronic lymphocytic leukemia (CLL) and small lymphocytic lymphoma (SLL) are considered the same entity. However, the clinical presentations are different. As yet, detailed molecular-genetic comparisons between CLL and SLL are scarce. In this study, we evaluated the presence of genetic abnormalities and (immunoglobulin heavy chain variable
\end{abstract}

P. J. T. A. Groenen $(\bowtie) \cdot$ P. D. M. Rombout $\cdot$ M. de Prenter

C. Philipsen-Jansen · J. H. J. M. van Krieken

Department of Pathology,

Radboud University Nijmegen Medical Centre,

Geert Grooteplein Zuid 10,

6525 GA Nijmegen, The Netherlands

e-mail: p.groenen@pathol.umcn.nl

R. Raymakers

Department of Hematology,

Radboud University Nijmegen Medical Centre,

Nijmegen, the Netherlands

R. Raymakers

Department of Hematology, UMC Utrecht,

Utrecht, the Netherlands

L. Kossen · A. G. van Kessel - M. Stevens-Kroef

Department of Human Genetics,

Radboud University Nijmegen Medical Centre,

Nijmegen, The Netherlands

T. Feuth

Department of Epidemiology, Biostatistics and HTA,

Radboud University Nijmegen Medical Centre,

Nijmegen, The Netherlands

J. W. R. Meijer

Department of Pathology, Rijnstate Hospital Arnhem,

Arnhem, The Netherlands genes) $I G H V$ use and mutation status in lymph node samples of patients presenting with lymphadenopathy alone and, therefore, classified as SLL $(n=21)$ or with persisting lymphadenopathy and absolute lymphocyte counts of $\geq 5 \times$ $10^{9} / \mathrm{L}$ and, therefore, classified as CLL/SLL $(n=17)$. In addition, blood samples of CLL patients were evaluated $(n=82)$. The majority of lymph node samples from SLL patients $(66 \%)$ showed unmutated $I G H V$ genes. This occurrence was significantly higher than in CLL (29\%). Poor risk genetic aberrations (11q-, 17p-, and +12) were more prevalent in the SLL (45\%) as compared to CLL (22\%). Samples from CLL/SLL patients exhibited almost equal frequencies of poor risk genetic aberrations (53\%), but lower frequencies of unmutated $I G H V$ genes $(35 \%)$, as compared to SLL. In summary, SLL not only differs clinically from CLL, but also genetically, with a higher propensity of adverse molecular parameters in SLL. CLL and SLL likely encompass a phenotypic spectrum within one disease entity.

Keywords $I G H V$ genes $\cdot$ Mutation status $\cdot$ Genetic aberrations $\cdot$ Lymphoma $\cdot$ Leukemia

\section{Introduction}

According to the World Health Organization (WHO) classification system, chronic lymphocytic leukemia (CLL) and small lymphocytic lymphoma (SLL) are considered the same entity. The definition of an entity in this system is primarily based on clinical, morphologic, phenotypic, and genetic criteria. CLL and SLL patients differ at least clinically, i.e., SLL patients present with 
only lymphadenopathy and/or splenomegaly. The absolute lymphocyte count (ALC) in peripheral blood does not exceed $5 \times 10^{9} / \mathrm{L}$ in SLL patients, whereas in CLL patients ALC is defined as $\geq 5 \times 10^{9} / \mathrm{L}$. In contrast, lymph node morphology and immunophenotype are similar in CLL and SLL patients. As yet, detailed molecular-genetic comparisons are scarce.

The clinical course and the overall survival rate of patients with CLL/SLL are largely related to molecular parameters, such as specific genetic abnormalities, mutation status of the immunoglobulin heavy chain variable genes $(I G H V)$, and the use of specific $V H$ genes [1-7]. Patients with unmutated $I G H V$ gene usage exhibit a relatively poor prognosis with overall survival times between 8 and 15 years. The use of IGHV3-21 represents an additional adverse prognostic factor, independent of its mutation status [8-13]. Genetic abnormalities may provide additional prognostic information. CLL/SLL patients with deletions of the 11q22 (ATM) and/or 17p13 (TP53) regions, for example, exhibit a significantly shorter overall survival time than those with other genetic abnormalities (such as deletions in 13q) or patients without detected abnormalities. CLL/SLL patients with a trisomy of chromosome 12 exhibit a relatively poorer outcome and, as such, appear to represent an intermediate risk group [3, 5, 14-16]. The prognostic information obtained from $I G H V$ gene use and mutation status on one hand and the genetic status on the other hand is complementary [7, 17-19]. In the HOVON68 study [20], high-risk CLL/SLL is defined by the presence of unmutated $I G H V$ genes, mutated $I G H V$ genes with use of IGHV3-21 [1, 2, 8, 11, 13], chromosome 17p or 11q deletions, and/or trisomy of chromosome $12[3,4,14$, 16]. We have used these criteria in the present study.

As of yet, only a few molecular-genetic studies in SLL have been reported [21-25], which may be due to the fact that the prevalence of SLL is relatively rare. In addition, lymph node samples from SLL patients are routinely examined in pathology laboratories, instead in immunology/hematology laboratories where testing of CLLassociated molecular-genetic prognostic parameters mostly takes place. Additionally, the use of fixed and paraffinembedded tissues, which is routine in pathology laboratories, may hamper molecular-genetic analyses due to the suboptimal DNA quality obtained from them [26]. For the evaluation of genetic aberrations in CLL, fluorescence in situ hybridization (FISH) with target-specific probes used on fresh blood samples is widely used [14]. FISH can be applied to small-sized clinical samples as well [27]. More recently, also multiplex ligation-dependent probe amplification (MLPA [28]) has been used as a comprehensive tool to detect genetic abnormalities in CLL/SLL [29]. Both FISH and MLPA have also been applied to SLL [21-25]. Biased and stereotypic use of heavy chain complementary determining region 3 has been observed in CLL/SLL, particularly for the IGH3-2I and IGH4-34 V-genes, which suggests the occurrence of antigen selection during the course of the disease [30-34]. A large study on stereotypic use in SLL cases has, to the best of our knowledge, not been performed.

Here, we have assessed prognostic relevant risk moleculargenetic parameters (a) in lymph node samples of SLL patients who did not show blood involvement, (b) in lymph node samples of CLL/SLL patients with persistent lymphadenopathy and lymphocyte counts exceeding the cutoff levels provided by the WHO, and (c) in peripheral blood samples of CLL patients (comprising all Rai stages, [35]). We found that the combination of $V H$ mutation status, IGHV3-21 use, and poor prognosis genetic aberrations yielded a higher prevalence in the SLL patients as compared to CLL patients. In order to generate a broader overview on the occurrence of adverse genetic aberrations and unmutated $I G H V$ genes in SLL, we have reviewed cases reported in the literature as well.

\section{Methods and materials}

\section{Patients and tissue samples}

In our studies, we included blood samples obtained from 82 patients diagnosed with CLL using standard morphologic and immunophenotypic criteria. The samples were collected before treatment of the patients. Based on the IGH gene clonality profiles, the percentage of monoclonal CLL cells of all the included cases was estimated to be high $(>90 \%)$. From these patients, 27 were referred to the Radboud University Nijmegen Medical Centre (RUNMC) and 55 to several regional hospitals in the Netherlands. In addition, we included diagnostic frozen lymph node samples histologically classified as CLL/SLL $(n=38)$. These lymph node samples were obtained from the archives of the Departments of Pathology of the RUNMC and Rijnstate Hospital Arnhem, the Netherlands. All samples were reviewed by an expert pathologist panel for lymphomas. The tumor load of all cases was estimated to be at least $60 \%$. Handling and assessment of the tissues used in this study were performed according to the code of adequate secondary use of human tissue [36]. The lymph node samples were categorized as either SLL (21 cases) or CLL/SLL (17 cases), based on ALC using a cutoff value of $5 \times 10^{9} / \mathrm{L}$ (according to the WHO classification). The CLL/SLL lymph nodes were derived from patients who presented predominantly with lymphadenopathy (8/17 cases) or from known CLL patients with persisting or increasing lymphadenopathy $(8 / 17$ cases). From one patient, no clinical information was available, except the ALC count. In all these latter patients, 
the ALC counts exceeded $\geq 5 \times 10^{9} / \mathrm{L}$. Lymphadenopathy was used as an indication for excision and, according to the WHO guidelines, its diagnosis was confirmed through histopathologic evaluation.

\section{DNA extraction procedures}

Frozen tissue sections (5-20 um) from lymph nodes were used to extract DNA via standard procedures, including proteinase $\mathrm{K}$ treatment and ethanol precipitation. From the blood samples, DNAs were extracted using a QIAcube robotic workstation, according to the instructions of the manufacturer (Qiagen, Venlo, The Netherlands). DNA sample concentration and quality were assessed by measurement of 260/280 $\mathrm{nm}$ ratio (using a NanoDrop2000 spectrophotometer; Isogen Life Sciences) and by polymerase chain reaction (PCR) amplification using the BIOMED2 control gene primer set [35]. All frozen tissue and blood samples yielded PCR-amplifiable DNAs of at least 600 nucleotides in length.

\section{Determination of IGH mutation status and VH use}

Clonality assays were performed through the amplification of IGH-VJ (FR1) and the IGH-leader using the multiplex BIOMED-2 PCR protocol [37] and the primers described by Fais et al. [38], respectively. PCR products were monitored through fluorescent gene scan analysis on an ABI 3730 platform (Life Technologies, Foster City, CA, USA). Subsequently, sequencing was performed on an ABI 3730 platform (Life Technologies), using at least two independently generated PCR products. The VDJ nucleotide sequences were aligned using the IMGTIgBLAST database $[39,40]$. A sequence homology cutoff of $98 \%$ was used to define the $V H$ mutation status. Homology to the nearest germline $V H$ gene was calculated starting at the first nucleotide 3 ' from the FR1 forward primer to the last codon (CDR3-IMGT codon 105/106/ 107, depending on exonuclease trimming) of the $I G H V$ gene $[41,42]$. In cases where the percentage of identity was close to $98 \%$, the percentage identity was determined from the first (FR1-IMGT codon 1) to the last codon as described above (using the IGH-leader PCR product). Care was taken that length of the sequenced PCR fragment corresponded to the length evaluated by gene scanning.

\section{Detection of genetic aberrations by FISH and MLPA}

DNAs extracted from the lymph node and blood samples were assessed using MLPA [28]. In some cases, cells were assessed by FISH as well. For FISH, commercially available probes for ATM (11q22), centromere 12,
D13S319 (13q14), and TP53 (17p13) were used according to the manufacturer's specifications (Abbott Molecular, Des Plaines, IL) and at least 200 interphase nuclei were scored by two independent investigators. MLPA was carried out according to the manufacturer's instructions (MRC-Holland Amsterdam, The Netherlands) using two specifically designed sets of probes for testing genetic aberrations in CLL, i.e., P037 and P038 [28]. Amplified products were analyzed by capillary electrophoresis on an ABI 3730 genetic analyzer (Life Technologies). In a previous study [29], we showed a perfect correlation between FISH and MLPA, provided that the abnormal clone was present in at least $10-20 \%$ of the cells.

\section{Statistical analysis}

A two-sided Fisher's exact test and exact linear trend test were used to identify significant differences between the three groups under investigation, i.e., lymph node samples of patients with SLL $(n=21)$, lymph node samples of patients with CLL/SLL $(n=17)$, and blood samples of patients with CLL $(n=82)$, with respect to putative adverse prognostic factors, as defined by the HOVON-68 study [20]. High-risk CLL/SLL is defined by the presence of unmutated $I G H V$ genes, mutated $I G H V$ genes with use of IGHV3-21, chromosome $17 \mathrm{p}$ or $11 \mathrm{q}$ deletions, and/or trisomy of chromosome 12.

\section{Results}

IGHV mutation status differs significantly among SLL and CLL samples

The IGHV mutation status of the different test samples is presented in Table 1 and Fig. 1a. This analysis revealed that a high percentage $(66 \%)$ of lymph node samples in the SLL group exhibited unmutated $V H$ genes, and that this percentage was different from the lower percentage (29\%) observed in the blood samples of the CLL patients. The CLL/SLL-derived lymph node samples yielded intermediate values $(35 \%)(P=0.003$ based on the exact linear trend test, two sided). Note that there is no overlap in cases between the SLL/CLL and the CLL patient groups. From one case included in the SLL/CLL group, a lymph node specimen and a later blood sample were available. In both samples, identical mutation rates and identical genetic aberrations were observed, indicating a full concordance between the lymph node and blood samples in this patient. Due to lack of blood samples of the other patients with SLL and CLL/SLL, concomitantly testing of blood and lymph node samples was not possible. 
Table 1 Molecular prognostic parameters in patients with SLL and CLL

\begin{tabular}{|c|c|c|c|c|}
\hline Molecular parameter & $\mathrm{SLL}^{\mathrm{c}}$ & CLL/SLL & CLL & $P$ value \\
\hline 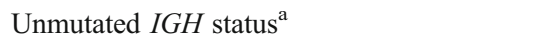 & $66 \%(14 / 21)$ & $35 \%(6 / 17)$ & $29 \%(24 / 82)$ & $0.002^{\mathrm{d}}$ \\
\hline Unmutated $I G H$ status and/or $\mathrm{V}_{\mathrm{H}} 3-21$ usage & $66 \%(14 / 21)$ & $35 \%(6 / 17)$ & $34 \%(28 / 82)$ & $0.012^{\mathrm{d}}$ \\
\hline \multicolumn{5}{|l|}{ Adverse prognostic factors } \\
\hline $\begin{array}{l}\text { Unmutated } I G H \text { and/or } \mathrm{V}_{\mathrm{H}} 3-21 \text { usage } \\
\text { and/or poor risk genetic aberrations }\end{array}$ & $71 \%(15 / 21)$ & $65 \%(11 / 17)$ & $43 \%(35 / 82)$ & $0.011^{\mathrm{e}}$ \\
\hline Poor risk genetic aberrations ${ }^{\mathrm{b}}$ & $45 \%(9 / 20)$ & $53 \%(9 / 17)$ & $22 \%(18 / 82)$ & $0.005^{\mathrm{e}}$ \\
\hline $\operatorname{del}(17 p)$ & $10 \%(2 / 20)$ & $24 \%(4 / 17)$ & $4 \%(3 / 82)$ & N.d. \\
\hline $\operatorname{del}(11 q)$ & $20 \%(4 / 20)$ & $6 \%(1 / 17)$ & $9 \%(7 / 82)$ & N.d. \\
\hline Trisomy 12 & $15 \%(3 / 20)$ & $24 \%(4 / 17)$ & $11 \%(9 / 82)$ & N.d. \\
\hline $\operatorname{del}(13 q)$ & $55 \%(11 / 20)$ & $71 \%(12 / 17)$ & $51 \%(42 / 82)$ & N.d. \\
\hline $\begin{array}{l}\text { Other genetic aberrations } \\
\text { (e.g., gain } 8 \mathrm{q} 24,+19 \text {, loss } 6 \mathrm{q} 25-26)\end{array}$ & $20 \%(4 / 20)$ & $0 \%(0 / 17)$ & $2 \%(2 / 82)$ & $0.013^{\mathrm{d}}$ \\
\hline No genetic aberrations ${ }^{\mathrm{f}}$ & $10 \%(2 / 20)$ & $0 \%(0 / 17)$ & $37 \%(30 / 82)$ & $<0.001^{\mathrm{e}}$ \\
\hline
\end{tabular}

$S L L$ small lymphocytic lymphoma, $C L L$ chronic lymphocytic leukemia

${ }^{a}$ Unmutated $I G H V$ genes, defined using the cutoff of higher or equal than $98 \%$ homology to the germline sequence

${ }^{\mathrm{b}}$ Poor risk genetic aberrations, as defined by the deletion of $11 \mathrm{q}, 17 \mathrm{p}$ and/or trisomy 12

${ }^{\mathrm{c}}$ From one SLL case (IGH unmutated), there was no material left for analysis of the genetic aberrations by MLPA

${ }^{\mathrm{d}} P$ value of comparison between the SLL and CLL group

${ }^{\mathrm{e}} P$ value of comparison between the CLL group and the SLL, SLL/CLL groups

${ }^{\mathrm{f}}$ As measured by MLPA

Poor risk genetic aberrations prevail in CLL/SLL and SLL lymph node samples

Genetic aberrations associated with adverse outcome in CLL (i.e., deletion of $11 \mathrm{q}, 17 \mathrm{p}$, and/or trisomy of chromosome 12, according to the criteria of the HOVON study [20]) occurred in about half of the lymph nodes from both the SLL and the CLL/SLL patients. No significant differences were observed between these two groups. Their incidence was, however, significantly different from those observed in the CLL blood samples (Table 1). In all except one case with a trisomy 12 and $\operatorname{del}(17 \mathrm{p})$, the adverse genetic aberrations were found to be isolated, i.e., not combined with other known adverse genetic aberrations. Interestingly, in the CLL/SLL group, there were more cases with $17 \mathrm{p}$ loss as compared to the other two patient groups, as exemplified in Fig. 1b. Loss of 13q was commonly observed, but we found no significant differences in its incidence between the three patient groups studied (Table 1 and Fig. 1b). The loss of $13 \mathrm{q}$ was seen both as an isolated genetic abnormality and in combination with adverse genetic abnormalities and/or an unmutated $I G H$ gene status (data not shown). Other recurrent genetic aberrations, such as gain of 8q24, trisomy of chromosome 19, and loss of 6q25-26, were more frequently observed in lymph nodes of the SLL patients as compared to the CLL/SLL cases. A lack of genetic abnormalities was significantly more frequent in CLL samples than in the lymph node samples derived from the SLL or CLL/SLL group (Table 1). From these data, we conclude that the lymph node specimens from SLL patients and CLL/SLL patients may represent a more advanced stage of disease and display pronounce genetic instability, which will most likely result from the inactivation of DNA damage response pathways (such as deletion of 11q22 that encompasses the $A T M$ gene).

\section{VH1 gene use is high in SLL samples}

Subsequent analysis of $I G H V$ gene use revealed a high percentage of $\mathrm{VHI}$ gene use in the SLL lymph node samples as compared to the other two groups (Table 2). This high percentage of $V H 1$ gene use can mainly be attributed to the high percentage of cases exhibiting $\mathrm{VH} 1$ 69 use (78\%). Cases that exhibited VH1-69 use were mostly, but not exclusively, associated with an unmutated $I G H V$ status [43]. In the SLL group and in the CLL/SLL group, seven and three cases with VH1-69 use were found, respectively, all unmutated. Within the CLL group, 9 out of 11 VH1-69 cases (including one case with bi-allelic VH1-69 unmutated rearrangements) were found to be unmutated.

Also, VH4 gene use occurred frequently in the SLL samples. Specifically, the use of VH4-39 was frequently seen in the SLL samples, while this use was rarely observed in the CLL samples studied (Table 2). Of interest is that the $V H 4-39$ SLL cases displayed different $D$ and $J$ segment use (data not shown). The use of VH4-34 was absent in the 21 
Fig. 1 a Occurrence of mutational status and combined molecular prognostic parameters in SLL and CLL. Poor risk genetic aberrations are defined in our study as the deletion of 11q, 17p, and/or trisomy 12 . Poor risk factors $(I G H+$ genetic) are defined by unmutated $I G H$ status and/or IGHV3-21 usage and/or poor risk genetic aberrations. b Occurrence of prognostic genetic parameters in SLL and CLL presented as compound bar chart a

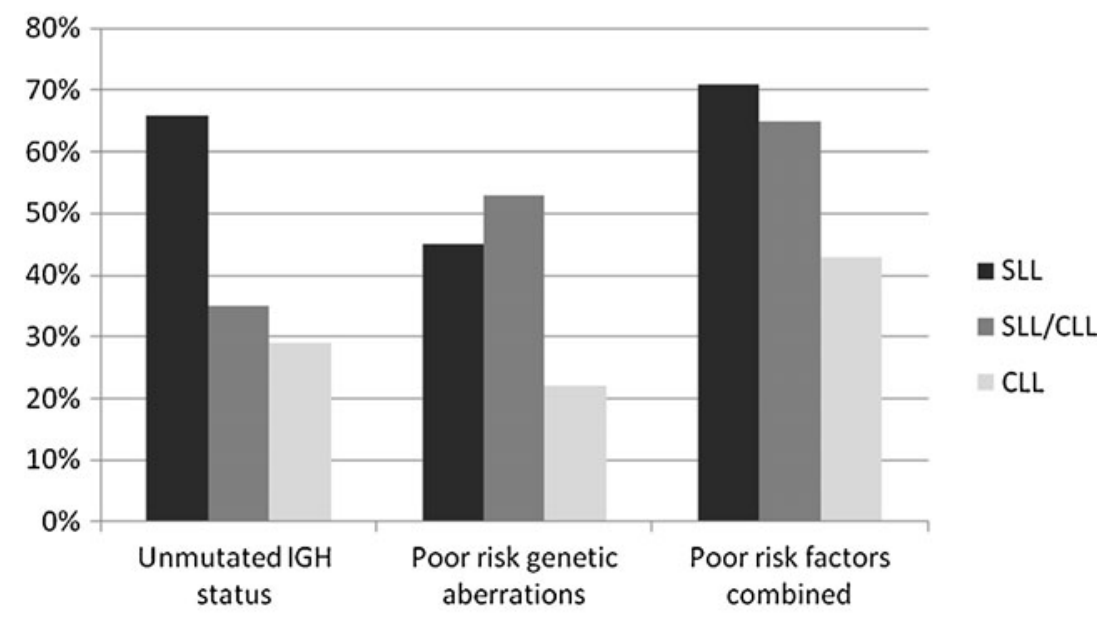

b

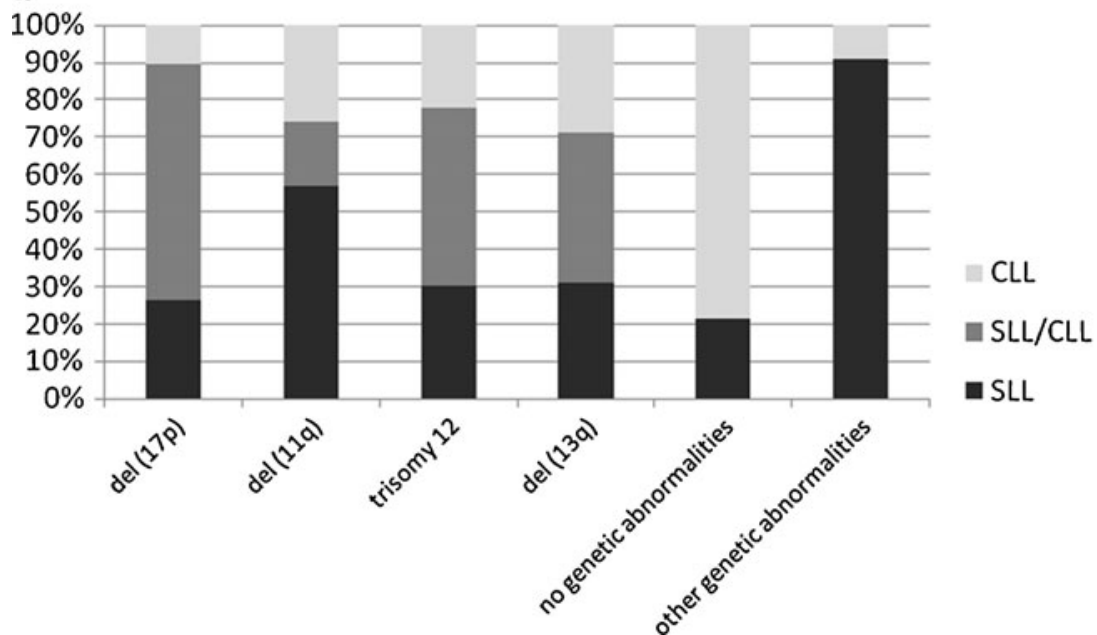

SLL samples studied, while biased stereotypic use of $\mathrm{VH} 4-$ 34 expressing cases is found in CLL [31]. In contrast to the CLL group, no VH3-21 use was observed nor in the SLL nor in the CLL/SLL group (Tables 1 and 2). Rearrangement of the second allele is a well-known phenomenon in leukemia and lymphoma $[44,45]$ and occurred in the three patient groups as well (Table 2).

Adverse genetic aberrations and IGHV mutations prevail in SLL samples

Combining the prognostic molecular parameters, i.e., IGH mutation status and $\mathrm{V}$-gene use, with the poor risk genetic aberrations, revealed a remarkably high occurrence in SLL as compared to CLL (Table 1). In the SLL group, 13 of the $14 I G H$-unmutated cases were evaluated by MLPA, 8 of these cases showed adverse genetic aberrations (Table 3). In contrast, only one out of seven $I G H V$-mutated cases showed adverse genetic aberrations, which was trisomy 12 (intermediate risk [14]). Del(17p) and del(11q), which are categorized as unfavorable markers, are found in the unmutated SLL cases. Also, in the other two groups, adverse genetic aberrations were specifically observed in the IGHV-unmutated cases. Overall, most of the VH1-69unmutated cases showed adverse genetic aberrations (Table 3). Although the number of cases studied is admittedly small, our findings indicate that the occurrence of adverse genetic aberrations is correlated to the mutation status, or even to $V$-gene use.

\section{Discussion}

We have evaluated the occurrence of prognostic moleculargenetic parameters in lymph node samples of patients with SLL/CLL. We categorized the samples in those that were derived from patients with predominant blood involvement (CLL), those that came from patients with both lymph node and blood involvement (CLL/SLL), and those that came from patients with predominantly lymph node involvement 
Table 2 Details on VH gene usage in SLL and CLL

\begin{tabular}{lrrr}
\hline Molecular parameter & \multicolumn{1}{l}{ SLL } & \multicolumn{1}{l}{ CLL/SLL } & \multicolumn{1}{l}{ CLL } \\
\hline VH1 usage & $43 \%(9 / 21)$ & $17 \%(3 / 18)$ & $30 \%(26 / 87)$ \\
$\mathrm{V}_{\mathrm{H}} 1-69$ usage & $78 \%(7 / 9)$ & $100 \%(3 / 3)$ & $46 \%(12 / 26)$ \\
VH2 usage & $10 \%(2 / 21)$ & $0 \%(0 / 18)$ & $6 \%(5 / 87)$ \\
$\mathrm{V}_{\mathrm{H}} 2-5$ usage & $100 \%(2 / 2)$ & $0 \%(0 / 0)$ & $60 \%(3 / 5)$ \\
$\mathrm{VH}_{3}$ usage & $19 \%(4 / 21)$ & $67 \%(12 / 18)$ & $43 \%(37 / 87)$ \\
$\mathrm{V}_{\mathrm{H}} 3-21$ usage & $0 \%(0 / 4)$ & $0 \%(0 / 12)$ & $19 \%(7 / 37)$ \\
$\mathrm{VH}_{4}$ usage & $29 \%(6 / 21)$ & $17 \%(3 / 18)$ & $20 \%(17 / 87)$ \\
$\mathrm{V}_{\mathrm{H}} 4-34$ usage & $0 \%(0 / 6)$ & $66 \%(2 / 3)$ & $41 \%(7 / 17)$ \\
$\mathrm{V}_{\mathrm{H}} 4-39$ usage & $50 \%(3 / 6)$ & $0 \%(0 / 3)$ & $6 \%(1 / 17)$ \\
VH5 usage & $0 \%(0 / 21)$ & $0 \%(0 / 18)$ & $1 \%(1 / 87)$ \\
VH6 usage & $0 \%(0 / 21)$ & $0 \%(0 / 18)$ & $1 \%(1 / 87)$ \\
Bi-allelic & $24 \%(5 / 21)$ & $18 \%(3 / 17)$ & $17 \%(14 / 82)$ \\
rearrangements & & & \\
\hline
\end{tabular}

$S L L$ small lymphocytic lymphoma, $C L L$ chronic lymphocytic leukemia The counts for $\mathrm{V}$ usage were based on the alleles with an Open Reading Frame (functional alleles) as such identified form the IMGT database. In two out of three (CLL/SLL lymph nodes) and in 9 out of 14 (regular CLL) bi-allelic cases, one of the two alleles was a nonproductive rearrangement. In the remaining cases (one CLL/SLL case and five CLL cases) both functional alleles were either both mutated or both unmutated. One of the CLL cases has bi-allelic IGHV1-69 rearrangements, both unmutated

[lymphocytosis $<5 \times 10^{9} / \mathrm{L}$ (SLL)]. An integrated analysis of $I G H V$ mutation status, $I G H V$ use, and the occurrence of recurrent adverse genetic aberrations were performed. Together, our data indicate that the SLL group exhibits a significantly higher prevalence of adverse prognostic

Table 3 Many adverse genetic aberrations in unmutated cases

\begin{tabular}{|c|c|c|c|}
\hline $\begin{array}{l}\text { Adverse genetic aberrations } \\
\text { and mutational status }\end{array}$ & SLL & CLL/SLL & CLL \\
\hline $11 \mathrm{q}-$ in mutated cases & $0 \%(0 / 7)$ & $0 \%(0 / 11)$ & $0 \%(0 / 56)$ \\
\hline $17 \mathrm{p}$ - in mutated cases & $0 \%(0 / 7)$ & $9 \%(1 / 11)$ & $2 \%(1 / 56)$ \\
\hline+12 in mutated cases & $14 \%(1 / 7)$ & $27 \%(3 / 11)$ & $9 \%(5 / 56)$ \\
\hline $11 \mathrm{q}$ - in unmutated cases & $31 \%(4 / 13)$ & $16 \%(1 / 6)$ & $29 \%(7 / 24)^{\mathrm{a}}$ \\
\hline $17 \mathrm{p}$ - in unmutated cases & $15 \%(2 / 13)$ & $50 \%(3 / 6)$ & $7 \%(2 / 24)^{a, b}$ \\
\hline+12 in unmutated cases & $15 \%(2 / 13)$ & $16 \%(1 / 6)$ & $17 \%(4 / 24)^{\mathrm{a}, \mathrm{b}}$ \\
\hline $\begin{array}{r}\text { 11q- in IGHVI-69 } \\
\text { unmutated cases }\end{array}$ & $28 \%(2 / 7)$ & $33 \%(1 / 3)$ & $44 \%(4 / 9)$ \\
\hline $\begin{array}{r}17 \mathrm{p} \text { - in IGHVI-69 } \\
\text { unmutated cases }\end{array}$ & $0 \%(0 / 7)$ & $33 \%(1 / 3)$ & $11 \%(1 / 9)$ \\
\hline $\begin{array}{r}+12 \text { in IGHVI-69 } \\
\text { unmutated cases }\end{array}$ & $14 \%(1 / 7)$ & $33 \%(1 / 3)$ & $11 \%(1 / 9)$ \\
\hline
\end{tabular}

$S L L$ small lymphocytic lymphoma, $C L L$ chronic lymphocytic leukemia

${ }^{\text {a }}$ Unmutated cases include the unmutated IGHV3-21 and IGHV1-69 cases (but not the mutated IGHV3-21 cases, or IGHV1-69 cases)

${ }^{\mathrm{b}}$ One case displayed both trisomy 12 and $\operatorname{del}(17 \mathrm{p})$ molecular-genetic markers as compared to CLL. This striking difference can mainly be attributed to the high prevalence of $I G H V$-unmutated cases in the SLL group. We also found a high frequency of adverse genetics aberrations in lymph node samples of the SLL, which was comparable to the CLL/SLL group.

As yet, only limited information is available on the molecular-genetic makeup of lymph nodes of SLL patients, which is mainly due to the fact that the occurrence of SLL is rare. The M.D. Anderson Cancer Center reviewed retrospectively CLL/SLL patient records on characteristics at presentation, treatment modalities, and clinical outcome [22]. It was found that patients with SLL exhibited lower rates of unmutated $I G H V$ genes, which are discordant with our data. This difference in outcome is most likely due to the limited number of cases included in both studies. The higher percentage of genetic abnormalities that we observed in lymph node samples of both the SLL and CLL/SLL groups, as compared to those present in the blood CLL samples, was not noted by Flanagan et al. [46]. Instead, they found similar frequencies of these genetic abnormalities in lymphoid tissues as compared to peripheral blood or bone marrow samples. They did, however, not make a distinction between patients with SLL and CLL. The relatively high frequency of genetic alterations in the lymph node samples of both the SLL and the SLL/CLL cases might be a reflection of the compartment or microenvironment in which they arise in. It is noteworthy in this respect that not all genetic alterations tested are increased in the lymph node specimens, as exemplified by 13q- deletions and to a lesser extent trisomy 12 (Fig. 1b). Genetic markers and $I G H V$ mutation status were recently assessed in patients with SLL and CLL by the group of Bastard, using methods comparable to ours [23]. They found that trisomy 12 was the most frequent genetic aberration in a cohort of 22 SLL cases. Taking our data and those reported in the literature together (Table 4), it can be concluded that there is no specific increase in trisomy 12 frequency in these patient groups.

Deletion of $17 \mathrm{p}$ is the less frequently occurring adverse genetic aberration in SLL. In the CLL/SLL lymph node group in the present study, however, a high number of $17 \mathrm{p}$ - cases $(24 \%)$ was observed as compared to the $4 \%$ of $17 \mathrm{p}$ - found in CLL patients (which is in line with $7 \%$ of $17 \mathrm{p}$ - found by Döhner et al. [14]). The high prevalence of $17 \mathrm{p}$ - in the CLL/SLL group is most likely due to the fact that these patients were either known as CLL patients with persistent or increasing lymphadenopathy, or as patients predominantly presenting with lymphadenopathy (and an ALC of $\geq 5 \times 10^{9} / \mathrm{L}$ ). The latter category most likely represents CLL patients with a more advanced stage of disease and discerns them from the classical CLL patients. The high prevalence of $17 \mathrm{p}-$ 
Table 4 Literature review of the genetic aberrations and IGHV mutation status in SLL

\begin{tabular}{|c|c|c|c|c|c|}
\hline SLL & $\begin{array}{l}\text { Aoun et al. [25] } \\
\text { Bahler et al. }[21]^{\mathrm{b}}\end{array}$ & $\begin{array}{l}\text { Tsimberidou } \\
\text { et al. [22] }\end{array}$ & $\begin{array}{l}\text { Daudignon } \\
\text { et al. [23] }\end{array}$ & $\begin{array}{l}\text { Garcia } \\
\text { et al. [24] }\end{array}$ & This study \\
\hline del $17 p$ & $1 / 14$ & $3 / 44$ & $1 / 22$ & $1 / 27$ & $2 / 20$ \\
\hline del 11q & $1 / 14$ & $7 / 44$ & $4 / 22$ & $7 / 27$ & $4 / 20$ \\
\hline Trisomy 12 & $2 / 14$ & $8 / 44$ & $8 / 22$ & $6 / 27$ & $3 / 20$ \\
\hline del $13 q$ isolated & $1 / 14$ & N.d. & $2 / 22$ & $13 / 27$ & $9 / 20$ \\
\hline$I G H V$ mutated & $4 / 10$ & $25 / 33$ & $11 / 17$ & $10 / 26$ & $8 / 21$ \\
\hline$I G H V$ unmutated & $6 / 10$ & $8 / 33$ & $6 / 17$ & $16 / 26$ & $13 / 21$ \\
\hline
\end{tabular}

Note that lymph node specimens were evaluated by Aoun et al. [25], Daudignon et al. [23], Garcia et al. [24], and the current study. Bone marrow biopsies were evaluated by Tsimberidou et al. [22]. In this table, the FISH data (and not the cytogenetics data) of the Tsimberidou study were included because of reasons of comparison to the other studies

${ }^{a}$ The study that reports the SLL data on the genetic aberrations

${ }^{\mathrm{b}}$ The study that reports the SLL data on the IGHV mutation status

supports the findings reported by the group of Trbusek, who demonstrated that up to $20 \%$ of treated CLL patients acquired new TP53 mutations [47, 48].

Only a limited number of $I G H V$ mutation studies have been performed in SLL (Table 4). Some of these studies reported an overrepresentation of mutated cases [21, 22], whereas other studies have reported an overrepresentation of unmutated SLL cases [20,23]. In a study reported by Leuenberger et al. [49], using lymph node samples from both patients with SLL and CLL, frequent unmutated cases as well as a frequent use of $V H 3$ followed by $V H 4$ and $V H 1$ respectively were observed. $V H 1-69$ was, similar to the SLL cases included in our study, the most prevalent $\mathrm{VH}$ gene detected. Taken together with the literature data (listed in Table 4), it is evident that, as yet, only a limited number of SLL cases has been studied in detail at the molecular-genetic level, which may explain the (partly) contradictory results outlined above, and may preclude an in-depth evaluation of the occurrence of relevant prognostic molecular-genetic parameters in SLL.

Whether stereotypic patterns of somatic hypermutation specifically occur in SLL is not thoroughly investigated yet. In CLL, multiple subsets of patients appear to exist that display similar immunoglobulin gene use with almost identical complementary determining regions [31]. In our SLL study group, we did not observe VH3-21 or VH4-34 use, whereas CLL cases with this $V$ gene use often display characteristic stereotypic patterns of hypermutation [32]. IGHVI-69 use is frequently observed in CLL, often in an unmutated form. IGHV1-69 use was also frequently encountered in our SLL patient group. Of the seven unmutated IGHV-1-69 SLL cases, five exhibited specific $D$ and $J$ segment use, which is also seen in "stereotypic" CLL patients. This latter result indicates that stereotypy may be involved in SLL as well. For a better evaluation of $\mathrm{VH}$ use and the occurrence of stereotypic patterns of somatic hypermutation in SLL, a combined study effort is needed.

In summary, we have assessed the occurrence of several molecular-genetic prognostic factors in clinically distinct groups of CLL/SLL patients. By doing so, we found that the prevalence of adverse prognostic genetic aberrations and unmutated $I G H V$ genes is significantly higher in patients with SLL as compared to those with CLL. Our data support the current WHO classification and illustrate that CLL and SLL likely encompass a phenotypic spectrum within one disease entity.

Acknowledgments The authors thank Annemiek van Raaij, Department of Pathology RUNMC, for expert technical assistance and Dr. Annet Simons, Department of Human Genetics RUNMC, for critically reading the manuscript.

Conflict of interest The authors declare that they have no conflict of interest.

\section{References}

1. Hamblin TJ, Davis Z, Gardiner A, Oscier DG, Stevenson FK (1999) Unmutated $\mathrm{Ig} \mathrm{V}(\mathrm{H})$ genes are associated with a more aggressive form of chronic lymphocytic leukemia. Blood 94:1848-1854

2. Damle RN, Wasil T, Fais F, Ghiotto F, Valetto A, Allen SL et al (1999) IgV gene mutation status and CD38 expression as novel prognostic indicators in chronic lymphocytic leukemia. Blood 94:1840-1847

3. Oscier DG, Gardiner AC, Mould SJ, Glide S, Davis ZA, Ibbotson RE et al (2002) Multivariate analysis of prognostic factors in CLL: clinical stage, IGVH gene mutational status, and loss or mutation of the p53 gene are independent prognostic factors. Blood 100:1177-1184

4. Kröber A, Seiler T, Benner A, Bullinger L, Brückle E, Lichter P et al (2002) V(H) mutation status, CD38 expression level, genomic aberrations, and survival in chronic lymphocytic leukemia. Blood 100:1410-1416 
5. Kröber A, Bloehdorn J, Hafner S, Bühler A, Seiler T, Kienle D et al (2006) Additional genetic high-risk features such as $11 \mathrm{q}$ deletion, $17 \mathrm{p}$ deletion, and V3-21 usage characterize discordance of ZAP-70 and VH mutation status in chronic lymphocytic leukemia. J Clin Oncol 24:969-975

6. Haferlach C, Dicker F, Schnittger S, Kern W, Haferlach T (2007) Comprehensive genetic characterization of CLL: a study on 506 cases analysed with chromosome banding analysis, interphase FISH, $\operatorname{IgV}(\mathrm{H})$ status and immunophenotyping. Leukemia 21:2442-2451

7. Grever MR, Lucas DM, Dewald GW, Neuberg DS, Reed JC, Kitada $\mathrm{S}$ et al (2007) Comprehensive assessment of genetic and molecular features predicting outcome in patients with chronic lymphocytic leukemia: results from the US Intergroup Phase III Trial E2997. J Clin Oncol 25:799-804

8. Tobin G, Thunberg U, Johnson A, Thörn I, Söderberg O, Hultdin $M$ et al (2002) Somatically mutated Ig V(H)3-21 genes characterize a new subset of chronic lymphocytic leukemia. Blood 99:2262-2264

9. Albesiano E, Maffei R, Dao-Ung LP, Wiley J, Vilpo J, Laurell A et al (2006) Strikingly homologous immunoglobulin gene rearrangements and poor outcome in VH3-21-using chronic lymphocytic leukemia patients independent of geographic origin and mutational status. Blood 107:2889-2894

10. Fält S, Merup M, Tobin G, Thunberg U, Gahrton G, Rosenquist R et al (2005) Distinctive gene expression pattern in VH3-21 utilizing Bcell chronic lymphocytic leukemia. Blood 106:681-689

11. Thorsélius M, Kröber A, Murray F, Thunberg U, Tobin G, Bühler A et al (2006) Strikingly homologous immunoglobulin gene rearrangements and poor outcome in VH3-21-using chronic lymphocytic leukemia patients independent of geographic origin and mutational status. Blood 107:2889-2894

12. Bomben R, Dal Bo M, Capello D, Benedetti D, Marconi D, Zucchetto A et al (2007) Comprehensive characterization of IGHV3-21-expressing B-cell chronic lymphocytic leukemia: an Italian multicenter study. Blood 109:2989-2998

13. Ghia EM, Jain S, Widhopf GF 2nd, Rassenti LZ, Keating MJ, Wierda WG et al (2008) Use of IGHV3-21 in chronic lymphocytic leukemia is associated with high-risk disease and reflects antigendriven, post-germinal center leukemogenic selection. Blood 111:5101-5108

14. Döhner H, Stilgenbauer S, Benner A, Leupolt E, Krober A, Bullinger L et al (2000) Genomic aberrations and survival in chronic lymphocytic leukemia. N Engl J Med 343:1910-1916

15. Anagnostopoulos A, Fassas A, Tsezou A (2006) Clinical, immunophenotypic, and molecular profiling of trisomy 12 in chronic lymphocytic leukemia and comparison with other karyotypic subgroups defined by cytogenetic analysis. Cancer Genet Cytogenet 168:109-119

16. Mittal AK, Hegde GV, Aoun P, Bociek RG, Dave BJ, Joshi AD et al (2007) Molecular basis of aggressive disease in chronic lymphocytic leukemia patients with $11 \mathrm{q}$ deletion and trisomy 12 chromosomal abnormalities. Int J Mol Med 20:461-469

17. Hallek M, Cheson BD, Catovsky D, Caligaris-Cappio F, Dighiero $\mathrm{G}$, Dohner $\mathrm{H}$ et al (2008) Guidelines for the diagnosis and treatment of chronic lymphocytic leukemia: a report from the International Workshop on Chronic Lymphocytic Leukemia updating the National Cancer Institute-Working Group 1996 guidelines. Blood 111:5446-5456

18. Morilla A, Gonzalez de Castro D, Del Giudice I, Osuji N, Else M, Morilla R et al (2008) Combinations of ZAP-70, CD38 and IGHV mutational status as predictors of time to first treatment in CLL. Leuk Lymphoma 49:2108-2115

19. Rassenti LZ, Jain S, Keating MJ, Wierda WG, Grever MR, Byrd JC et al (2008) Relative value of ZAP-70, CD38, and immunoglobulin mutation status in predicting aggressive disease in chronic lymphocytic leukemia. Blood 112:1923-1930
20. A randomized phase III study in previously untreated patients with biological high-risk CLL: fludarabine + cyclophosphamide (FC) versus FC + low-dose alemtuzumab. Christian Geisler (Nordic Group), Marinus van Oers (HOVON CLL Group); http://www.hovon.nl

21. Bahler DW, Aguilera NS, Chen CC, Abbondanzo SSH (2000) Histological and immunoglobulin VH gene analysis of interfollicular small lymphocytic lymphoma provides evidence for two types. Amer J Pathol 157:1063-1070

22. Tsimberidou AM, Wen S, O'Brien S, McLaughlin P, Wierda WG, Ferrajoli A et al (2007) Assessment of chronic lymphocytic leukemia and small lymphocytic lymphoma by absolute lymphocyte counts in 2,126 patients: 20 years of experience at the University of Texas M.D. Anderson Cancer Center. J Clin Oncol 25:4648-4656

23. Daudignon A, Poulain S, Morel P, Penther D, Parmentier F, Bouchindhomme B et al (2010) Increased trisomy 12 frequency and a biased IgVH 3-21 gene usage characterize small lymphocytic lymphoma. Leuk Res 34:580-584

24. Garcia CF, Hunt KE, Kang H, Babb A, Gale JM, Vasef MA et al (2010) Most morphologic features in chronic lymphocytic leukemia/small lymphocytic lymphoma (CLL/SLL) do not reliably predict underlying FISH genetics or immunoglobulin heavy chain variable region somatic mutational status. Appl Immunohistochem Mol Morphol 18:119-127

25. Aoun P, Blair HE, Smith LM, Dave BJ, Lynch J, Weisenburger DD et al (2004) Fluorescence in situ hybridization detection of cytogenetic abnormalities in B-cell chronic lymphocytic leukemia/small lymphocytic lymphoma. Leuk Lymphoma 45:15951603

26. Groenen PJTA, Blokx WAM, Diepenbroek C, Burgers L, Visinoni F, Wesseling $P$ et al (2011) Preparing pathology for personalized medicine: possibilities for improvement of the pre-analytical phase. Histopathology 59(1):1-7

27. Caraway NP, Thomas E, Khanna A, Payne L, Zhang HZ, Lin E et al (2008) Chromosomal abnormalities detected by multicolor fluorescence in situ hybridization in fine-needle aspirates from patients with small lymphocytic lymphoma are useful for predicting survival. Cancer 114:315-322

28. Schouten JP, McElgunn CJ, Waaijer R, Zwijnenburg D, Diepvens F, Pals G (2002) Relative quantification of 40 nucleic acid sequences by multiplex ligation-dependent probe amplification. Nucleic Acids Res 30:e57

29. Stevens-Kroef M, Simons A, Gorissen H, Feuth T, Weghuis DO, Buijs A et al (2009) Identification of chromosomal abnormalities relevant to prognosis in chronic lymphocytic leukemia using multiplex ligation-dependent probe amplification. Cancer Genet Cytogenet 195:97-104

30. Messmer BT, Albesiano E, Efremov DG, Ghiotto F, Allen SL, Kolitz J et al (2004) Multiple distinct sets of stereotyped antigen receptors indicate a role for antigen in promoting chronic lymphocytic leukemia. J Exp Med 200:519-525

31. Stamatopoulos K, Belessi C, Moreno C, Boudjograh M, Guida G, Smilevska T et al (2007) Over $20 \%$ of patients with chronic lymphocytic leukemia carry stereotyped receptors: pathogenetic implications and clinical correlations. Blood 109:259-270

32. Murray F, Darzentas N, Hadzidimitriou A, Tobin G, Boudjogra M, Scielzo C et al (2008) Stereotyped patterns of somatic hypermutation in subsets of patients with chronic lymphocytic leukemia: implications for the role of antigen selection in leukemogenesis. Blood 111:1524-1533

33. Stamatopoulos K (2010) Antigens in CLL: themes and variations. Blood 115:3855-3856

34. Rosén A, Murray F, Evaldsson C, Rosenquist R (2010) Antigens in chronic lymphocytic leukemia-implications for cell origin and leukemogenesis. Semin Cancer Biol 20(6):100-409 
35. Rai KR, Sawitsky A, Cronkite EP, Chanana AD, Levy RN, Pasternack BS (1975) Clinical staging of chronic lymphocytic leukemia. Blood 46:219-324

36. Code of Conduct: "Code for adequate secondary use of tissue (2001)" by a subcommittee of the Federation of Medical Scientific Societies (FMWV): http://www.federa.org/?s=1\&m=82

37. Van Dongen JJ, Langerak AW, Bruggemann M, Evans PA, Hummel M, Lavender FL et al (2003) Design and standardization of PCR primers and protocols for detection of clonal immunoglobulin and T-cell receptor gene recombinations in suspect lymphoproliferations: report of the BIOMED-2 Concerted Action BMH4-CT98-3936. Leukemia 17:2257-2317

38. Fais F, Ghiotto F, Hashimoto S, Sellars B, Valetto A, Allen SL et al (1998) Chronic lymphocytic leukemia B cells express restricted sets of mutated and unmutated antigen receptors. J Clin Invest 102:1515-1525

39. Davi F, Rosenquist R, Ghia P, Belessi C, Stamatopoulos K (2008) Determination of IGHV gene mutational status in chronic lymphocytic leukemia: bioinformatics advances meet clinical needs. Leukemia 22:212-214

40. Lefranc MP, Giudicelli V, Ginestoux C, Jabado-Michaloud J, Folch $\mathrm{G}$, Bellahcene $\mathrm{F}$ et al (2009) IMGT, the international ImMunoGeneTics information system. Nucleic Acids Res 37((Database issue)):D1006-D1012

41. Ghia P, Stamatopoulos K, Belessi C, Moreno C, Stilgenbauer S, Stevenson F et al (2007) European Research Initiative on CLL. ERIC recommendations on IGHV gene mutational status analysis in chronic lymphocytic leukemia. Leukemia 21:1-3

42. Ghia P, Rosenquist R, Davi F (eds) (2009) Immunoglobulin gene analysis in chronic lymphocytic leukemia, 1st edn. Wolters Kluwer Health/ Lippincott Williams \& Wilkins, Baltimore
43. Galligan L, Catherwood MA, Matthews C, Morris TC, Alexander HD (2008) Mutated IgHV1-69 gene usage represents a distinct subgroup associated with indolent disease in chronic lymphocytic leukemia. Leuk Lymphoma 49:763-768

44. van Dongen JJ, Wolvers-Tettero IL (1991) Analysis of immunoglobulin and $\mathrm{T}$ cell receptor genes. Part I: basic and technical aspects. Clin Chim Acta 198:1-91

45. van Dongen JJ, Wolvers-Tettero IL (1991) Analysis of immunoglobulin and $\mathrm{T}$ cell receptor genes. Part II: possibilities and limitations in the diagnosis and management of lymphoproliferative diseases and related disorders. Clin Chim Acta 198:93-174

46. Flanagan MB, Sathanoori M, Surti U, Soma L, Swerdlow SH (2008) Cytogenetic abnormalities detected by fluorescence in situ hybridization on paraffin-embedded chronic lymphocytic leuke$\mathrm{mia} / \mathrm{small}$ lymphocytic lymphoma lymphoid tissue biopsy specimens. Am J Clin Pathol 130:620-627

47. Malcikova J, Smardova J, Rocnova L, Tichy B, Kuglik P, Vranova V, Cejkova S, Svitakova M, Skuhrova Francova H, Brychtova Y, Doubek M, Brejcha M, Klabusay M, Mayer J, Pospisilova S, Trbusek M (2009) Monoallelic and biallelic inactivation of TP53 gene in chronic lymphocytic leukemia: selection, impact on survival, and response to DNA damage. Blood 114:5307-5314

48. Trbusek M, Malcikova J, Mayer J (2011) Selection of new TP53 mutations by therapy in chronic lymphocytic leukemia. Leuk Res 35(7):981-982

49. Leuenberger M, Frigerio S, Wild PJ, Noetzli F, Korol D, Zimmermann DR et al (2010) AID protein expression in chronic lymphocytic leukemia/small lymphocytic lymphoma is associated with poor prognosis and complex genetic alterations. Mod Pathol 23:177-186 